\title{
Olhos e coração na lírica galego-portuguesa
}

Yara Frateschi Vieira Universidade Estadual de Campinas

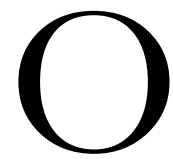

s dois termos, "olhos" e "coração", separadamente, já têm sido reconhecidos como vocábulos importantes na construção da concepção amorosa na lírica galego-portuguesa. A cada um deles dedicaram-se estudos, com uma perspectiva geral ou concentrados no seu uso por um determinado trovador, ${ }^{1}$ analisando a sua frequência, os campos semânticos em que figuram, as relações que se podem estabelecer com expressões semelhantes empregadas nas líricas amorosas latina, provençal e francesa, ou com concepções presentes na literatura religiosa latina e vernácula que precede a floração poética na Península Ibérica ou lhe é contemporânea, e mesmo na literatura filosófica e científica da época.

Não tenho, porém, conhecimento de nenhum estudo que se tenha ocupado das relações que unem os dois termos entre si na lírica galegoportuguesa. Fora do âmbito peninsular, no entanto, contamos com alguns trabalhos que examinaram o emprego e o sentido desses termos, dentro do campo que se poderia denominar a "psicologia amorosa", na literatura vernácula, lírica e épica, do Ocidente europeu nos séculos XII e XIII. Desses, o mais específico é o artigo de Ruth $\mathrm{H}$. Cline que, partindo de algumas imagens e expressóes presentes no Cligès de Chrétien de Troyes, as quais descrevem as funções dos olhos e do coração no início e desenvolvimento

${ }^{1}$ A respeito dos olhos, cf. VASCONCELOS, 2004, p. 521-540; TAVANI, 1988, p. 28 e ss.; SANSONE, 1961, p. 165-189; SOUTO CABO, 1988, p. 401-420; PÉREZ BARCALA, 2004, p. 595-626. A respeito do coração: AMADO, 2006; VIEIRA, 2006; VIEIRA, 2010, p. 673-683. 
do sentimento amoroso, lança mão de uma considerável rede de relaçôes literárias, em sentido amplo, temporal e espacialmente, para lhes identificar as fontes. ${ }^{2}$ Essas descriçōes representam, segundo Cline, cinco concepçōes que, embora conhecidas por literaturas precedentes, constituem uma novidade na literatura provençal e do norte da França no século XII. Elas são:

1. O amor é súbito e poderoso, e ocorre geralmente com o primeiro olhar.

2. Os olhos são não apenas perceptores da beleza, mas também agentes, ao promoverem o amor.

3. Enquanto agentes, os olhos funcionam como uma arma que ataca, através dos olhos da amada, dentro do coração.

4. Existe uma disputa entre o coração e os olhos.

5. O coração pode escapar do corpo para estar com a amada. ${ }^{3}$

A fim de colocar as concepções galego-portuguesas que envolvem o par "olhos/coração" contra o pano de fundo de um contexto históricoliterário mais amplo e relevante para a sua constituição como discurso poético, faço aqui um brevíssimo resumo do trabalho de Cline. Ela dedicase, como já disse, a investigar as possíveis fontes para cada um dos motivos apontados: os dados que levanta, e que cobrem um período vasto na literatura ocidental como um todo, levam-na a concluir que, de forma geral, os cinco motivos descritos já se encontravam na literatura grega e alexandrina, na filosofia platônica, na Biblia e na literatura cristã dela derivada; os escritores latinos clássicos, contudo, não parecem ter estado muito atentos ao papel dos olhos no desenvolvimento do amor, embora o tema do amor à primeira vista já seja ovidiano; ${ }^{4}$ por outro lado, na

${ }^{2}$ CLINE, 1972, p. 263-297. Cf. também KOLB, 1958, p. 18-38; HANFORD, 1911, p. 161-165; PAOLI, 1991, p. 233-244; WOLF, 1972, p 626-649. Ainda que a relação olhos/coração não seja o seu foco, são fundamentais, para a sua compreensão dentro de um amplo contexto histórico-literário, os dois estudos de ERTZDORFF, 1962, p. 249-301 e 1965, p. 6-46.

${ }^{3}$ CLINE, 1972, p. 263.

${ }^{4}$ CLINE, 1972, p. 278. 
literatura árabe de Al-Andalus, os olhos “tinham um enorme poder” e é, aliás, possível reconhecer a influência platônica na imagem dos olhos como espelho da alma, empregada por Ibn Hazm em O Colar da Pomba; $;^{5}$ além disso, considerando o poder mágico atribuído ao olhar pelos árabes, não é de surpreender que na sua poesia seja frequente a metáfora do olhar como uma arma que, lançada pelos olhos da amada, atravessa os olhos do amante, ferindo-o no coração. A literatura cristã, por sua vez, seria responsável pela difusão de dois motivos: o debate entre o coração e os olhos e o coração que escapa do corpo para estar com a amada. ${ }^{6}$ Nesse sentido, é importante lembrar que na literatura cristã pós-agostiniana Deus vem habitar no coração do homem, desde que ele se tenha para isso suficientemente purificado. ${ }^{7}$

A minha intenção com esse resumo não é revisar as conclusões a que chegou a Autora desse artigo, fundamental para o estudo da relação entre "olhos e coração" na literatura medieval provençal e francesa. Como ela explora o emprego que desse binômio fizeram principalmente os romances corteses e a lírica cortês da Provença e do Norte da França, repertório reconhecidamente familiar aos trovadores galego-portugueses, isso nos facilita retraçar as linhas, correspondentes ou não, por estes privilegiadas para a configuração de uma "psicologia do início e do desenvolvimento do sentimento amoroso".

Apenas um reparo, contudo, indispensável para que as relações entre olhos e coração se tornem mais nítidas, dentro dessa fisio-psicologia do amor: Cline lembra que o papel da concepção dos olhos como agentes no despertar do amor é de origem platônica; no entanto, como se sabe, a obra de Platão chegou aos séculos XII e XIII, não na sua versão original e completa, mas em grande parte através de citações e comentários feitos pelos escritores latinos clássicos, especialmente Cícero, e pelos doutrinadores cristãos. ${ }^{8}$ Não se deve esquecer, tampouco, que estes lançaram mão de diversas fontes na

\footnotetext{
${ }^{5}$ CLINE, 1972, p. 280.

${ }^{6}$ CLINE, 1972, p. 285.

${ }^{7}$ Cf. KOLB, 1958, p. 29 e ss.

${ }^{8}$ Cf. KOLB, 1958, p. 29-30.
} 
elaboração daquilo que poderíamos chamar a "teoria da imaginação" medieval, e que uma das principais contribuições, utilizada inclusive por Agostinho, foi trazida pelas ideias aristotélicas a respeito da produção e da reprodução da imagem. ${ }^{9}$ Aristóteles, assim como a tradição médica em que se baseia, supunha que dois órgãos estivessem envolvidos na produção das imagens e da memória: o coração, que recebe todas as impressões derivadas do exterior, e o cérebro, ao qual a informação é transmitida e no qual é então guardada. ${ }^{10}$ Embora o pensamento medieval tenha desenvolvido, posteriormente, concepções bastante elaboradas a respeito do processo de formação da imagem e da relação dos sentidos exteriores com o que se passou a chamar "sentidos interiores", ${ }^{11}$ situados nas diferentes regiões do cérebro, manteve-se na literatura religiosa e na poesia profana a concepção não só aristotélica, mas também bíblica, de que o coração sediava as faculdades emotivas e cognoscitivas do homem. ${ }^{12}$ É interessante observar nesse sentido que, na linguagem lírica das Confissóes, Agostinho prefere substituir o termo anima, por ele empregado nos escritos filosóficos, pelo mais poético e mais bíblico cor. $^{13}$

${ }^{9}$ Cf. a esse respeito, BUNDY, 1970, p. 145-180; CARRUTHERS, 1990; SORABJI, 2004; ARISTOTE, 2000; ARISTOTLE, 2000.

${ }^{10}$ CARRUTHERS, 1990, p. 48. Cf. ARISTOTLE, 2000 (On the Soul: On Memory and Recollection, 450a27-30, p. 292-293): a edição francesa (ARISTOTE, 2000, p. 108, n. 12) acrescenta a seguinte nota à tradução desse texto: "Certains traducteurs comprennent: "la partie du corps qui possède <l'âme>”, mais l'âme n'est pas réellement localisée dans une partie donnée du corps (...). Il faudrait alors comprendre qu'il s'agit de l'âme sensitive. En tout état de cause, la signification du texte reste la même: c'est dans la région du coeur que les images sont retenues. Aristote y fera également allusion en 2, 453a15".

${ }^{11}$ Cf. WOLFSON, 1973, p. 250-311.

${ }^{12}$ Cf., sobre a polêmica medieval entre o coração e o cérebro como sede das "faculdades ou sentidos interiores", JACQUARt, 2003, p. 73-95.

${ }^{13}$ Cf. GUILlaUMONT, 1996, p. 55. Cf. também o levantamento do emprego de cor em toda a obra de Agostinho, em PEZA, 1962, p. 23-94. 
Podemos passar agora a examinar como se comportam esses dois termos na lírica amorosa galego-portuguesa. Limito-me aqui ao campo das cantigas de amor; naturalmente, é possível que a extensão do exame às cantigas de amigo revele algo distinto ou complementar, embora não me pareça ser esse o caso, à primeira vista. Fico por enquanto com as conclusóes, talvez incompletas, que me permitem as cantigas de amor.

Um levantamento realizado com a ajuda das ferramentas que nos oferece a base de dados MedDB 2.0.3, ${ }^{14}$ registra que os dois termos se encontram utilizados, conjuntamente, em 53 cantigas de amor. É certo que o número seria bem maior, se considerássemos também a conjunção de termos associados a "olhos", como as formas dos verbos "ver" ou "catar". Como estou interessada, porém, nos sentidos específicos atribuídos à relação dos "olhos", enquanto órgão externo da visão, e o "coração", enquanto sede do sentimento amoroso, não procurei por enquanto estender a investigação a esses outros casos.

Empregaram o par de termos nas cantigas de amor 31 trovadores, sendo que duas cantigas constam como de atribuição anônima (Vid. Anexo, lista das cantigas).

Pelo que se pode observar, o emprego não se concentra especificamente num determinado período, pois há trovadores mais antigos e mais tardios. Quanto à geografia, talvez predominem os portugueses, mas isso pode não significar muito, se considerarmos que muitos deles têm passagem sabida

${ }^{14}$ Base de Datos da Lírica Galego-Portuguesa (MedBD) versão 2.0.3, Centro Ramón Piñeiro para a Investigación en Humanidades (http://www.cirp.es/), consultada em 6/9/2008 e 2/12/2008. Como as cantigas estão reproduzidas nessa base de dados com a ortografia das edições utilizadas, obtêm-se 37 cantigas em que co-ocorrem "olhos" e "coraçon"; 4 em que se encontram "olhos" e "coraçom"; 9 com "ollos" e "coraçon"; e 4 com "olhus" e "coraçon" (destas 4, uma é a cantiga 97.30 de Martim Soares, já registrada com a ocorrência de "olhos" e "coraçon": por esse motivo, computam-se apenas 3). Não co-ocorrem "ollos" e "coraçom", "olhus" e "coraçom", nem "ollus" e "coraçon" ou "coraçom". 
pela corte castelhana. Por outro lado, há alguns trovadores que se destacam com maior número de cantigas onde co-ocorrem os dois termos: D. Dinis, com cinco, Vasco Gil com quatro, Fernão Garcia Esgaravunha, João Garcia de Guilhade, João Soares Coelho e Pero Garcia Burgalês, com três cada, e os demais com duas ou apenas uma.

No entanto, a maior distinção que se nota nessas cantigas diz respeito à forma de articulação dos dois termos; em algumas, eles estão explicitamente relacionados um ao outro e essa relação é desenvolvida com maior ou menor elaboração; em outras, porém, os dois termos, embora coexistam na mesma cantiga, não se articulam e podem mesmo estar empregados apenas em fórmulas de uso corrente. Como os últimos casos são em menor número, estão marcados no Apêndice com NA. São, portanto, 19 cantigas dentre 53 , ou seja, $35.8 \%$ do total. Como já disse, não foram computados os casos em que o tema da visão é também desenvolvido através de outros vocábulos, o que restringe o nosso corpus a um grupo pequeno de ocorrências específicas, mas obviamente não insignificantes. A restrição permite-nos enfocar alguns casos que poderão mais tarde servir de parâmetro para a consideração das cantigas em que o tema é tratado também a partir de termos como "ver" ou "catar".

Em algumas das cantigas onde os termos não se articulam, o motivo dos "olhos" ou do "coração" aparece dentro de uma fórmula, como lume d'estes olhos meus, coita do meu coraçon (157.39 e 42); chorand'enton dos olhos meus, ben desejav'enton/ d'ela no meu coraçon (72.13); porque vus amo mais ... ca os olhos meus? Senhor de min e de meu coraçon (79.50); lume dos olhos meus, que de coraçon vos servi sempr'... (96.5) etc.; ou então a relação entre ambos fica apenas sugerida: pois eu de vós os meus olhos partir, por mal de min e do meu coraçon (106.13).

Nas demais cantigas, como já disse, a articulação entre os termos se faz de forma ora mais explícita ora menos; de forma mais convencional ou mais inovadora.

Dentre os motivos identificados por Cline, encontram-se os seguintes: 
- O amor nasce com o primeiro olhar e é uma força poderosa: por exemplo (Osoiro Eanes, 111.1): Cuidei eu de meu coraçon/ que me non podesse forçar... Mais forçaron-mi os olhos meus/ e o bon parecer dos seus; (D. Dinis, 25.87): Punh'eu, senhor, quanto poss'em quitarl d'em vós cuidar este meu coraçom/ que cuida sempr'em qual vos vi, mais nom/ poss'u per rem nem mi nem el forçar...

- Os olhos são agentes, no sentido de que são responsáveis pela visão prazerosa da amada: (Fernão Padron, 45.2) Os meus olhos, que mia senhorl foron veer... Quanto prazer viron enton; (Vasco Gil, 152.8): Quand'eles [meus olhos] viron mia senhorl muit'ouveron én gran sabor; (João Garcia de Guilhade, 70.42): mays os meus olhos quer eu ben/ e ja sempre Deus amarey;/ ca mi mostrou quen oj'eu vi:/ ay! que parecer oj'eu vi! O papel dos olhos enfatiza-se, nesse caso, quando são tratados como elementos autônomos da pessoa do amante e independentes da sua vontade. ${ }^{15}$

- O coração do amante pode unir-se ao coração da amada: a forma mais radical desse motivo é representada pelo coração que realmente sai do peito para ficar junto à dama; exemplos mais concretos da imagem foram primeiramente utilizados no romance cortês francês e, na lírica provençal, por Bernart de Ventadorn e Jaufre Rudel. ${ }^{16} \mathrm{Na}$ lírica galego-portuguesa, poucos trovadores elaboraram em toda a sua extensão os aspectos físicos que decorreriam do impulso espiritual do coração do amante para estar junto da amada. Entre eles, João Airas de Santiago (63.43), Pai Gomes Charinho (114.28), Roi Martins do Casal (145.5) e D. Dinis (25.73), numa cantiga cujas ressonâncias de J. Rudel e Bernart de Ventadorn já foram apontadas ${ }^{17}$ a cantiga de Roi Martins do Casal, de que só nos resta uma estrofe, aponta, além do motivo da separação do coração do corpo do amante para ir

${ }^{15}$ Cf. a respeito da autonomia dos olhos, o trabalho de SOUTO CABO, 1988.

${ }^{16}$ Cf. ERTZDORFF, 1965, p. 9 e ss.

${ }^{17}$ FERRARI, 1984, p. 41-43. 
onde está a senhora, o da "troca de corações", motivo também explorado pelo romance cortês: Ora, senhor, muy [ben] leda ficade:/ $d[e]$ mir, pesar non vos filhe $d[e]$ min, / ca me vou eu, e non levo d'aquy/ meu coraçon. E, por Deus, enviadel o vosso mygo, e faredes bom sen:l sse non, ben certa seede, senhor, / que morrerey, tant' ey de vós amor. Um exemplo a contrario encontra-se em Airas Nunes (14.11), que parece inclusive ironizar o motivo, ressaltando as impossibilidades fisiológicas por ele implicadas: o poeta interpela o coração, que o mata de amor, e pergunta-lhe com quem ficará, depois da sua morte, pois não pode separar-se dele: vv. 8-11: Ora que eu moiro, con quen ficades? / Vós con ela, par Deus, non ficaredes, / e se eu moiro migo morreredes, / ca vós noit'e dia migo ficades. Alguns trovadores preferem tratar da união dos corações sem sentirem a necessidade de referir que o coração tem de sair do peito do amante para unirse ao da amada, e assim passam por cima dos detalhes narrativos mais concretos para se concentrarem apenas na constatação de que o seu coração não pode separar-se dela: isso deixa margem para que se entenda também que o coração não pode deixar de pensar nela (Nuno Eanes Cêrzeo, 104.9): nen meu coraçon nunca o de vos partirei; (Martim Moxa, 94.12): cuidar me tolh'o dormir e o sén, / ca non poss'end'o coraçon partir ... se viss'ela o meu coraçon tan ben/ com'el ela, dever-sia doer/ d'el e de min.

- O motivo da disputa entre os olhos e o coração surgiu, na literatura latina medieval, enquanto gênero, como um debate sobre a relativa responsabilidade dos olhos ou do coração no pecado; depois foi empregado, geralmente já sem a forma do debate, mas apenas como um conceito, na literatura cortês, onde os olhos são responsabilizados pelo amor. ${ }^{18} \mathrm{Na}$ lírica galegoportuguesa, aparecem frequentemente formas que podem ser consideradas ecos enfraquecidos dessa disputa: os trovadores interpelam os olhos, como se fossem autônomos da sua vontade, por terem contemplado a beleza da dama e por isso terem forçado o seu coração, também ele autônomo, a amá-la (Guilhade, 70.42;

${ }^{18}$ Cf. HANFORD, 1911. 
Martim Soares, 97.30); às vezes procuram vingar-se deles (João Soares Coelho, 79.38; 79.40). Uma fórmula que revela a presença subliminar desse debate é por mal d'estes olhos meus ou outras expressões similares, que, como sabemos, são muito frequentes.

- O motivo dos olhos que funcionam como arma, por exemplo, uma seta, que atinge o coração dos amantes, não se encontra na lírica galego-portuguesa; na verdade, ele aparece mais desenvolvido no romance cortês do que na lírica provençal ou francesa. Cline chama a atenção para a sua presença na poesia árabe de Al-Andalus. ${ }^{19}$

Esta listagem, com os seus exemplos comprobatórios fragmentários, não nos deve fazer concluir que a lírica galego-portuguesa apenas recolheu motivos, ou fragmentos de motivos, da lírica transpirenaica, e os utilizou de forma não integrada ou mais ou menos aleatória.

Embora esse emprego revele que os motivos já tinham sido absorvidos de forma a se tornarem quase formulaicos, algumas cantigas desenvolvem, no entanto, de forma bastante elaborada, um ou mais dentre eles, deixando-nos entender que tinham ainda vitalidade suficiente para serem empregados com certa novidade. Vou ocupar-me aqui de apenas três, a fim de não exorbitar do tempo disponível. Começo por uma cantiga de Martim Moxa (94.12): ${ }^{20}$

\author{
O gran prazer e gran viç' en cuidar \\ que sempr' ouvi no ben de mia senhor, \\ mi a fazen ja tan muito desejar, \\ que moir' e non perco coitas d' amor; \\ 5 pero aven que algua sazon \\ arç' e mi afog' e moiro por que non \\ senç' u me dol nen sei en que travar.
}

${ }^{19}$ CLINE, 1972, p. 290-291.

${ }^{20}$ As cantigas são reproduzidas de acordo com a lição aceita pela MedBD2.0.3. Indicam-se no lugar oportuno as instâncias em que optei por outra lição. 
E por esto non leixei pois a amar

e servir ben e faze-lo milhor,

10 ca sempr' amor per ben se quer levar, e o pequeno e o grande e o maior, quaes el quer, eno seu poder son: pois assi é, semelha-mi razon de a servir e seu ben aguardar.

15 ¡Ai, Deus, tal ben quen o podess' aver de tal senhor qual min en poder ten! Pero que tom' en cuidar i prazer, cuidar me tolh' o dormir e o sén, ca non poss' end' o coraçon partir,

20 ca mi a faz sempr' ant' os meus olhos ir cada u vou, e, u a vi, veer.

Mais tanto sei, se podesse seer: se viss' ela o meu coraçon tan ben com' el ela, dever-s' ia doer

25 d' el e de min, poi-lo viss'; e por én am' eu e trob', e punh' ?na servir: que entenda, pois meu cantar oir, o que non posso nen lh' ouso a dizer. E non dev' omen seu cor encobrir

30 a quen sabe que o pode guarir; de mais u lh' outro non pode valer. v. 6 - Picchio, ard'e mh afog'; Nobiling, até mh-afogu'e; Nunes, atee mh-afrijo (vid. notas 21 e 22).

Não nos deve surpreender que esse trovador culto, versado na literatura eclesiástica, nas escrituras e na lírica provençal, ${ }^{21}$ esteja entre os que

${ }^{21}$ Cf. o estudo da sua temática e linguagem poética em PICCHIO, 1968, p. 81ss. Cf. também o que dele diz Nobiling: "Não é com um poeta desinteressante que lidamos aqui. Ele ama a reflexão séria e domina as formas, mesmo as difíceis e novas que imita em parte dos provençais". (NOBILING, 2007, p. 226). NUNES, 1972, p. 296-298. 
revelam familiaridade com os motivos já mencionados e os articule de maneira elaborada e original, no contexto da lírica galego-portuguesa. Vamos deixar de lado as duas primeiras estrofes, já de si bastante inovadoras, por apresentarem alternadamente uma sintomatologia amorosa expressivamente concreta nos seus efeitos físicos (vv. 6-7: arç' e mi afog'e moiro por que non senç'u me dol nen sei en que travar ${ }^{22}$ ) e uma caracterização generalizante e abstrata do amor enquanto força que atinge de forma igual a todos os homens (segunda estrofe). O tema que nos interessa aqui comparece explicitamente na terceira estrofe, vv. 17-21: Pero que tom' en cuidar i prazer,/ cuidar me tolh' o dormir e o sén,/ ca non poss' end'o coraçon partir,/ ca mi a faz sempr' ant'os meus olhos ir/ cada u vou, e u a vi, veer. A visão da amada gera, portanto, uma imagem que se deposita no coração do amante; uma vez ali, é fonte de prazer tal que, paradoxalmente, se transforma em sofrimento: o poeta perde o sono e a razão por "cuidar" nela, isto é, por não poder apagar dentro do seu coração a imagem que o seduz e que ele tem, por outro lado, sempre diante dos olhos - poderemos entender então que a imagem se projeta de dentro do coração do amante para fora, para diante dos seus olhos físicos, que continuam a vê-la, mesmo quando ela não está presente? Não se trata aqui do motivo do coração do poeta que sai do peito para estar junto à amada; é antes ela, enquanto imagem, que habita no seu coração: por isso, o poeta não pode evitar que o coração cuide nela, pois é o órgão que sedia a faculdade cogitativa e a imagem está dentro dele o tempo todo. Essa imagem do coração que "vê" a dama, que dentro dele habita, pode evocar também, de mais a mais num trovador que era clérigo, o oculus cordis agostiniano, ${ }^{23}$ isto é, o sentido

${ }^{22} \mathrm{O}$ v. 6 recebeu leitura diversa segundo os editores, que optam por formas como até mh-afogu'e (NOBILING, 2007, p. 227); o texto em $B$ 891, porém, autoriza a lição acolhida pelo MedDB2.0.3: arç'e mi afog' (que PICCHIO, 1958, p. 128, lera ard'e mh afog'). NUNES, 1972: atee m'afrijo.

${ }^{23}$ P. ex.: De vera rel., XIX, 37 (PL 34 I37 fim): Hinc iam cui oculi mentis patent, nec pernicioso studio vanae victoriae caligant atque turbantur, facile intelligit, (...); Enarr. in Ps. XVI, 2 (PL 36 I46 in.): Oculi mei videant aequitatem: 
interior que é capaz de ver a Deus dentro do coração humano, de larga tradição na literatura cristã. ${ }^{24}$ Por outro lado, porém, ainda na linha da alternância entre concretude física e abstração espiritual das estrofes anteriores, não é apenas com o sentido interior que o poeta contempla a amada, mas também com os seus olhos físicos voltados para o mundo exterior: a imagem da dama, assim projetada, adquire uma concretude que se refere também ao deslocamento espacial do poeta (cada u vou) e à reprodução do lugar onde a viu pela primeira vez $(u$ a vi). $\mathrm{O}$ trovador manifesta em seguida o desejo de que a amada pudesse ver o seu coração, da mesma forma como o seu a vê a ela, e que então se apiedasse dele: vv. 22-25: Mais tanto sei, se podesse seer:/ se viss' ela o meu coraçon tan ben/com'el ela, dever-s' ia doer/ d'el e de min, poi-lo viss' (...) - o coração, enquanto sede do amor e lugar onde habita a imagem da senhora, torna-se então também ele algo concreto, que pode ser visto: não só o coração do poeta pode ver a dama enquanto imagem, mas ela mesma deveria ser capaz de vê-lo. X. von Ertzdorff, referindo-se a cansós de Folquet de Marselha, observa que na sua poesia as expressões relativas ao coração decoram-se com figuras "visíveis". E cita como exemplo versos que se deixam aproximar dos de Martim Moxa: ins

cordis utique oculi. Apud PEZA, 1962, p. 75. Cf. também KOLB, 1958, p. 30: "Augustin also kennt das innere Auge, das Auge des Herzes, das sich auf die innere Schau des dem äusseren Auge unsichtbaren Gottes richtet”.

${ }^{24}$ Cf. M. CANÉVET, 1953.

${ }^{25}$ Cit. por ERTZDORFF, 1965, p. 34, segundo a edição de S. Stronski, Cracóvia, 1910. Na edição online de P. Squillacioti, em Rialto (20.ii.2002), 155.23, v. 41: qu'inz el cor remir sa faisso. <http:/www.rialto.unina.it/ FqMars/155.23 (Squillacioti).htm> (consultada em 2.12.2008).

${ }^{26}$ ERTZDORFF, 1965, p. 25. Squillacioti (cf. n. 25): 155.8, v. 9: qu’inz el cor port, domna, vostra faisson; vv. 13-20: per merce.us prec que.us gardes de l'ardor, / qu'eu ai paorl de vos mout major que de me; / e pois mos cors, domna, vos a dinz se, / si mals l'en ve, / puois dinz es, sofrir lo.us cove:/ e per so faitz del cors so que.us er bon/ e.l cor gardatz si com vostra maison. 
e'l cor remir sa faisso ${ }^{25}$ e qu'ins e'l cor port, dona, vostra faisso. ${ }^{26}$ Este último verso é seguido de uma imagem cujo grau de concretude é mais elevado ainda: o poeta pede à dama que preserve o seu coração do incêndio (a imagem do coração que arde de amor é, aliás, canônica), pois ela mesma está lá dentro e poderá sair ferida. Por isso, deve considerar o coração do amante como a sua casa - e tratá-lo com gentileza: Per merce.us prec que.l gardetz del'ardor, / Qu' ieu ai paor/ De vos mout major que de me, / E pos mos Cor, dona, vos a dinz sel Si mals li.n vel Pos dinz etz, sufrir lo. us cove!/ Empero faitz del Cors so que.us er bo/ E.l Cor gardatz si qom vostra maizo. É preciso ter em mente, também, que as imagens relativas ao coração, na literatura mística, mantiveram sempre um forte caráter físico e visível: as almas santas favorecidas por visões imaginárias creram sempre na extração real do seu coração e na sua substituição por um novo coração, embora os teólogos antigos e modernos não tenham admitido a realidade material da troca de coraçōes. ${ }^{27}$ Moxa é mais comedido, porém: ele apenas deseja que a dama possa ver o seu coração e "doer-se do coração e do poeta”. Poderíamos pensar que a imagem já se tinha cristalizado ou que o poeta galego-português preferisse uma forma mais discreta ou menos vistosa, mais de acordo com o seu dizer poético em geral. ${ }^{28}$ Aliás, a alternância entre concretude e abstração que percorre as quatro estrofes desemboca numa fiinda de caráter axiomático.

Muitas vezes os trovadores, seguros como estão de que a sua alusão cairá em ouvidos aos quais essas imagens e concepções são familiares, julgam inútil e mesmo contraproducente, em termos poéticos, explicitar as relações que lhes estão subjacentes. Assim, em lugar de retraçar todo o percurso do enamoramento, como o faria uma psicologia da percepção e da imaginação, basta-lhes concentrar-se num certo ponto, cuja força expressiva exploram. A cantiga 25.5, de D. Dinis, é um bom exemplo disso:

27 CABASSUT, 1953.

${ }^{28}$ PICCHIO, 1968, p. 66-74, chama a atenção para a tendência de Moxa a um estilo mais "contido", ou mais "discreto", mesmo nas suas cantigas de escárnio. 
A mha senhor que eu por mal de mi vi, e por mal d' aquestes olhos meus, e por que muitas vezes maldezi mi e o mund' e muitas vezes Deus,

5 des que a nom vi nom er vi pesar d'al, ca nunca me d' al pudi nembrar.

A que mi faz querer mal mi medes e quantos amigos soia aver, e desasperar de Deus, que mi pes,

10 pero mi tod' este mal faz sofrer, des que a nom vi nom ar vi pesar d'al, ca nunca me d'al pudi nembrar.

A por que mi quer este coraçom sair de seu logar e por que ja

15 moir' e perdi o sem e a razom, pero m' este mal fez e mais fará, des que a nom vi nom ar vi pesar d' al, ca nunca me d' al pudi nembrar (Sigo a ed. de Lang XXVII, que mantém, nos vv. $11 \mathrm{e}$ 17, forma idêntica à do v. 5 (des que a nom vi), exigida pelo metro, pelo sentido e conforme a $B 523$ e $V 106$.$) .$

Nos quatro versos iniciais das estrofes 1 e 2, o poeta elabora o tema do amor como abominação tal que o faz maldizer a tudo: os seus olhos, a si mesmo, o mundo e Deus, os amigos. O primeiro verso do refrão (des que a nom vi nom ar vi pesar/ d'al) parece continuar a atitude de revolta $\mathrm{e}$ rejeição dos versos anteriores, como se o poeta finalmente tivesse conseguido deixar de ver a dama e não mais sofresse por isso: desde que a não vê, nada mais lhe causa sofrimento, ela era a única causa do seu pesar. O segundo verso do refrão, porém, destrói essa possibilidade interpretativa: d'al, ca nunca me d'al pudi nembrar, ou seja, ele não sofre pesar por nenhuma outra coisa, porque a sua lembrança continua totalmente dominada pela imagem da amada, que não só se deposita no coração do amante, mas ocupa-o por completo, impedindo que ele tenha memória de 
qualquer outra coisa. Além dos versos de João Soares Coelho, que a cantiga dionisina ecoa, como já o observara Lang, ${ }^{29}$ poder-se-ia propor um modelo anterior para essa expressão do amor como um sentimento omnívoro, que retira ao amante todas as demais conexões que ele possa ter com o mundo material e espiritual: trata-se da canção da cotovia, de Bernart de Ventadorn, que começa por referir, aliás, que a dama lhe tomou o coração: Tout m'a mo cor, et tout m'a me,/ E se mezeis' e tot lo mon;/ E can se.m tolc, no.m laisset rel Mas dezirer e cor volon. ${ }^{30}$ Mas, ao contrário da cansó bernartiana, na qual o poeta se despede do amor e parte em exílio, sem saber para onde (qu’eu m'en vau, chaitius, no sai on), a cantiga dionisina reafirma a impossibilidade de escapar o sujeito da total subordinação a esse "fantasma" ${ }^{1}$ todo poderoso que lhe ocupa o coração e a memória.

O processo do enamoramento e da instalação do amor, como um sentimento que oscila entre o prazer que proporciona a contemplação da beleza e o sofrimento causado pela impossibilidade absoluta, estabelecida por princípio, de retribuição por parte da mulher amada, é concebido como um processo circular, que tende para a espiralação ao infinito: inicia-se pela contemplação prazerosa da dama e pela inscrição da sua imagem no coração; logo se transforma em sofrimento pela

29 "Uma maldição semelhante do mundo, de si mesmo e de Deus é expressa por João Coelho, CB 261 7-11: E quero mal quantos vos queren ben E os meos olhos con que vos eu vi, Mal quer a dês que me vos fez veer $\mathrm{E}$ a morte que me leixa viver $\mathrm{E}$ mal ao mundo por quant'i nasci." LANG, 1894 , p. cxxi (trad. minha).

${ }^{30}$ RIQUER, 2001, v. 1, n. 60, p. 384-387.

${ }^{31}$ Cf. AGAMBEN, 1998, p. 136-137: “... parce que la psychologie médiévale, et c'est là l'une des inventions les plus fécondes qu'elle ait léguées à la culture occidentale, conçoit l'amour comme un processus essentiellement fantasmatique, impliquant imagination et mémoire dans une quête obsédante autour d'une image peinte ou reflétée au plus intime de l'homme". 
cogitação excessiva; ${ }^{32}$ mas o amante anseia por rever novamente a dama, ainda sabendo que essa visão realimentará o seu sofrimento e o levará assim progressivamente ao paroxismo, do qual só o libertará a morte. Esses motivos paradoxais podem ser explorados, e frequentemente o são, através da sua justaposição, de forma elíptica e compacta. Uma cantiga que consegue tirar grande força expressiva dessa justaposição é a de João Garcia de Guilhade (70.22):

Estes meus olhos nunca perderán, senhor, gran coyta, mentr'eu vivo fôr; e direy-vos, fremosa mha senhor, d'estes meus olhos a coyta que an:

5 choran e cegan, quand'alguen non veen, e ora cegan por alguen que veen.

Guisado tẽen de nunca perder meus olhos coyta e meu coraçon, e estas coytas, senhor, mias son:

10 mays los meus olhos, por alguen veer, choran e cegan, quand'alguen non veen, e ora cegan por alguen que veen.

E nunca ja poderey aver ben, poys que amor ja non quer nen quer Deus;

15 mays os cativos d'estes olhos meus morrerán sempre por veer alguen: choran e cegan, quand'alguen non veen, e ora cegan por alguen que veen.

${ }^{32}$ Cf. ANDREAS CAPELLANUS, 1985, Lib. I, cap. 1, p. 54: "Amor est passio quaedam innata procedens ex visione et immoderata cogitatione formae alterius sexus (...)". AGAMBEN, 1998, p. 146, lembra a descrição perfeita que dessa immoderata cogitatio faz Dante na canção Amor, da che convien pur chio mi doglia: Ion non posso fuggir, ch'ella non vegnal ne l'imagine mia, / se non come il pensier che la vi mena./ L'anima folle, che al suo mal singegna, / com'ella è bella e rial così dipinge, e forma la sua pena:/ poi la riguarda, e quando ella è bien pienal del gran disio che de li occhi le tira, I incontro a sè s'adira, / cha fatto il foco ond'ella trista incende. DANTE ALIGHIERI, 1938, p. 163 [Rime, LXXXVII]. 
O grande efeito dessa cantiga está no refrão que, como já foi observado, é o verdadeiro núcleo inventivo do poema. ${ }^{33} \mathrm{O}$ movimento que nele se descreve é contrário à nossa expectativa quanto às possíveis consequências do ato de ver: segundo nos diz o poeta, os olhos cegam, porque as lágrimas, causadas pelo sofrimento de não poder ver a dama, o impedem de ver qualquer coisa; agora, porém, quando a veem, paradoxalmente cegam também. Penso que o segundo verso do refrão poderia ser compreendido de três formas: (1) o poeta cega, quando vê a dama, porque fica absorvido na contemplação, e ela impede-o de ver qualquer outra coisa; (2) os olhos cegam, deslumbrados pela excessiva beleza do objeto contemplado. Se assim for, a expressão de Guilhade transporia ao plano profano a experiência mística da contemplação divina, inatingível aos olhos humanos, a não ser de forma indireta e velada - por exemplo, através de uma nuvem, como a que envolve o Monte Sinai na aparição a Moisés, ${ }^{34}$ ou os discípulos de Jesus no episódio da transfiguração; ${ }^{35}$ ou ainda (3), como também o entende Sansone, ${ }^{36}$ a contemplação da dama torna ainda mais aguda a consciência da coita amorosa, provocando por isso novamente o pranto e a cegueira. Embora a segunda possibilidade me pareça bastante aliciante, penso que na verdade devemos entender o verso conforme a terceira opção, por causa da relação estabelecida no verso anterior entre chorar e cegar, e também porque podemos encontrar um emprego semelhante em outro trovador seu contemporâneo, Pai Soares de Taveirós, no poema talvez fragmentário $115.6^{\text {ter. }}$

Meus ollos, gran cuita d' amor

me dades vós, que sempr' assi

chorades; mais ja des aqui,

meus ollos, por Nostro Sennor,

non choredes, que vejades

a dona por que chorades.

33 SANSONE, 1961, p. 175.

${ }^{34}$ ÊXODO, 19.18.

${ }^{35}$ MATEUS, 17.5.

36 SANSONE, 1961, p. 175. 
Permitam-me retomar aqui o que já disse em outra ocasião acerca desse texto do trovador galego: "A afirmação de Pai Soares [non choredes, que vejades/a dona por que chorades] parece contraditória porque nos faz supor que o choro é consequência de ver, quando na verdade a consequência de ver é amar. A sequência desambiguizada seria portanto: 'amo, porque a vi; e porque a amo, choro', que não pode ser reduzida simplesmente a 'quando a vejo, choro'. Combinada com a falsa relação de causalidade e de consequência, existe também uma falsa combinação temporal, que nos faz supor que o amante chora toda vez que vê a dama, quando o que está pressuposto é que a visão dela num dado momento provocou o amor que, por sua vez, e em seguida, provoca as lágrimas, pela não correspondência ou pela ausência da mulher no campo da visão do amante ou por ambos os fatores". ${ }^{37}$

No caso da cantiga de Guilhade, a falsa estrutura argumentativa é: quando não veem a dama, os olhos choram por causa disso e de tanto chorar, cegam; e quando a veem, cegam porque a veem. Na verdade, a desambiguização far-se-ia aproximadamente assim: os meus olhos choram porque sofro quando não a vejo e por isso cego, isto é, fico impedido pelas lágrimas de ver; quando a vejo, porém, sou novamente ferido pela sua beleza e pelo amor que ela provoca, de modo que torno a chorar e a cegar. A expressão de todo o complexo de emoçôes e reações físicas e psicológicas é dada de forma elíptica, conseguindo-se assim um efeito retórico duplo: não só se enfatiza o impacto da visão e do amor sobre o poeta, mas também se consegue uma aparente contradição, através da forma falaciosa do encadeamento dos eventos.

Para concluir: os trovadores galego-portugueses já encontraram à sua disposição os motivos relacionados aos olhos e ao coração na lírica trovadoresca provençal e francesa, bem como na épica francesa. As concepções pressupostas pelo emprego poético - isto é, provenientes das teorias filosóficas, dos textos religiosos e médicos anteriores e contemporâneos a eles, poderiam não ter sido diretamente do seu conhecimento, e provavelmente não o foram - pelo menos de forma geral, universal e

${ }^{37}$ VIEIRA, 2005, t. II, p. 297-298. 
completa. Mas elas constituíam o horizonte de conhecimentos e de concepçōes relativos ao amor que os envolvia a todos, motivo pelo qual esses trovadores podiam sentir-se dispensados de explicitar os fundamentos e as minúcias implicadas no funcionamento dos órgãos sensoriais e dos "sentidos interiores", bem como da fisiologia e da psicologia humana no despertar do amor e na sua vivência. É esclarecedor que alguns desses motivos sejam apenas mencionados de leve ou simplesmente aludidos em algumas cantigas: sinal de que isso bastava para que fossem preenchidos os indícios, por ouvintes ou leitores que compartilhassem um contexto mais amplo de referências e de associações. Por outro lado, alguns trovadores, mesmo partindo das formulações veiculadas pela tradição, conseguem concentrá-las ou conjugá-las de forma inusitada ou aparentemente contraditória, obtendo assim visões surpreendentes do processo de enamoramento e dos efeitos psico-fisiológicos do sentimento amoroso naquele que o sofre.

\section{Bibliografia citada}

AGAMBEN, Giorgio. Parole e fantasme dans la culture occidentale (traduit de l'italien par Yves Hersant), Paris: Ed. Payot \& Rivages, 1998.

ANDREAS CAPELLANUS. De Amore. Tratado sobre el amor. Barcelona: El Festín de Esopo, 1985. Ed. e trad. de I. Creixell Vidal-Quadras.

AMADO, Teresa. Longe da vista não pode estar o coração. Comunicação apresentada no VI Colóquio da AHLM-SP, Coimbra, 19-21 out. 2006. (no prelo).

ARISTOTE. Petits traités d'histoire naturelle [Parva Naturalia], Trad. et présentation par Pierre-Marie Morel, Paris: Flammarion, 2000.

ARISTOTLE. On the Soul, Parva Naturalia, On Breath, Transl. by W. S. Hett. Cambridge, Ma.; Londres, Inglaterra: Harvard University Press, 2000 (Loeb Classical Library 288).

BUNDY, M. W. The Theory of Imagination in Classical and Mediaeval Thought, 2. ed. Folcroft, Pa.: Folcroft Library Editions, 1970 [1. ed. 1927] 
CABASSUT, A. Coeurs (échange de). Dictionnaire de Spiritualité Ascétique et Mystique, Doctrine et Histoire. Paris: Beauschesne, 1953. v. II, col. 1047.

CANÉVET, M. Sens Spirituel. Dictionnaire de Spiritualité Ascétique et Mystique, Doctrine et Histoire. Paris: Beauschesne, v. 14, 1953. cols. 599-617.

CARRUTHERS, M. J. The Book of Memory. Cambridge: Cambridge University Press, 1990.

CLINE, Ruth H. Heart and Eyes. Romance Philology, v. 25, n.3, 1972, p. 263-297.

DANTE ALIGHIERI. Le opere minori. Florença: Casa Editrice Adriano Salani, 1938. Ed. por G. L. Passerini.

ERTZDORFF, Xenia von. Das Herz in der lateinisch-theologischen und frühen volksprachigen religiösen Literatur. Beiträge zur Geschichte der deutschen Sprache und Literatur, v. 84, p. 249-301, 1962.

ERTZDORFF, Xenia von. Die Dame im Herzen und das Herz bei der Dame. Zur Verwendung des Begriffs "Herz" in der höfischen Liebeslyrik des 11. und 12. Jahrhunderts. Zeitschrift für deutsche Philologie, v. 84, p. 6-46, 1965 .

FERRARI, Ana. Linguaggi lirici in contatto: trobadors e trobadores. Boletim de Filologia, v. 29, p. 41-43, 1984.

GUILLAUMONT, A. "Les sens des noms du coeur dans l'Antiquité", em Id. Études sur la spiritualité de l'Orient chrétien, Bégrolles-en-Mauges: Abbaye de Bellefontaine, 1996 (Spiritualité Orientale, no. 66)

HANFORD, J. H. The Debate of Heart and Eye. Modern Language Notes, v. 26, n. 6, p. 161-165, 1911.

JACQUART, D. Coeur ou cerveau? Les hésitations médiévales sur l'origine de la sensation et le choix de Turisanus. Micrologus, v. 11: Il cuore, The Heart, p. 73-95, 2003.

KOLB, H. Der Begriff der Minne und das Entstehen der höfischen Lyrik. Tübingen: Max Niemeyer Verlag, 1958.

LANG, Henry R. Das Liederbuch des Königs Denis von Portugal. Halle a.S.: Max Niemeyer, 1894. 
NOBILING, Oskar. A edição do Cancioneiro da Ajuda, de Carolina Michaëlis de Vasconcelos. In: NOBILING, O. As Cantigas de D. Joan Garcia de Guilhade e Estudos Dispersos. Edição organizada por Yara F. Vieira. Rio de Janeiro: EdUFF, 2007.

NUNES, José Joaquim. Cantigas d'amor dos trovadores galego-portugueses. Ed. crítica, acompanhada de introdução, comentário, variantes e glossário. 2. ed. Lisboa: Centro do Livro Brasileiro, 1972.

PAOLI, G. La relation oeil-coeur: recherches sur la mystique amoureuse de Chrétien de Troyes dans Cligès. In: Le "cuer" au moyen âge (Réalité et Senefiance), (Senefiance, 30), Aix-en-Provence: Publ. du CUERMA, 1991. p. 233-244.

PÉREZ BARCALA, Gerardo. "Ay lume d'estes olhos meus". O lume, a descriptio amantium e o sufrimento amoroso na lírica galego-portuguesa". In: BREA, Mercedes (Ed.). O Cancioneiro da Axuda, cen anos despois. Santiago de Compostela: Xunta de Galicia, 2004. p. 595-626.

PEZA, E. de la. El significado de "cor" en San Agustin. Paris: Études Augustiniennes, 1962.

PICCHIO, Luciana S. (Ed.). Martin Moya. Le Poesie. Roma: Ed. dell' Ateneo, 1968.

RIQUER, Martín de. Los Trovadores. Historia literaria y textos. Barcelona: Editorial Ariel, 2001.

SANSONE, Giorgio. Temi e tecniche delle Cantigas d'amor de Joan de Guilhade. Annali - Istituto Orientale Sezione Romanza, Nápoles, v. 3, 1961, p. 165-189.

SORABJI, R. Aristotle on Memory, 4. ed. Chicago, The University of Chicago Press, 2004.

SOUTO CABO, José Antonio. Aproximaçom ao motivo dos olhos nas cantigas de amor e amigo. Agália, Santiago de Compostela, v. 16, 1988, p. 401-420. TAVANI, Giuseppe. A Poesia Lírica Galego-Portuguesa (trad. de Isabel Tomé e Emídio Ferreira). Lisboa: Editorial Comunicação, 1988. 
VASCONCELOS, Carolina Michaëlis. "Olhos verdes ... olhos de alegria”, In: VIEIRA, Yara F. et alii. Glosas Marginais ao Cancioneiro Medieval Português. Coimbra: Por Ordem da Universidade; Santiago de Compostela; Campinas: Editora da UNICAMP, 2004. p. 521-540.

VIEIRA, Yara Frateschi. Falácias do amor: o lirismo galego-português e a nova lógica. In: PARRILLA, C.-Pampín, M. (Ed.). Actas del IX Congreso Internacional de la Asociación Hispánica de Literatura Medieval. A Coruña: Toxosoutos, 2005. p. 287-298.

VIEIRA, Yara Frateschi. A configuração do "lugar amoroso" na cantiga de amor galego-portuguesa. VI Colóquio da AHLM-SP, 19-21 out. 2006 (no prelo).

VIEIRA, Yara Frateschi. O significado do "coração" na lírica amorosa galegoportuguesa. Actas del XII Congreso de la AHLM, Cáceres, 25-29 set. 2007; Cáceres: Universidad de Cáceres, 2010. p. 673-683.

WOLF, G. Der Topos “Augen des Herzes” - Versuch einer Deutung durch die scholastische Erkenntnistheorie. Deutsche Vierteljahrsschrift für Literaturwissenschaft und Geistesgeschichte, v. 46, n. 4, 1972, p. 626-649.

WOLFSON, H. A. Studies in the History of Philosophy and Religion. Cambridge, Ma.: Harvard University Press, 1973. 


\section{Resumo}

O presente artigo trata do papel que as cantigas de amor galegoportuguesas atribuem aos "olhos" e ao "coração", enquanto fatores importantes no processo de enamoramento. Em primeiro lugar, verifica-se a o sentido e a presença dos motivos associados a ambos os termos nas literaturas que poderiam tê-los transmitido à Península Ibérica e a sua relação com exemplos similares encontrados na lírica galego-portuguesa; em seguida, examinamse três cantigas de amor (Martim Moxa, $B$ 891/ V 475; D. Dinis, $B$ 523/ V 106; João Garcia de Guilhade, $A$ 237), procurando determinar os usos específicos dos motivos nessa lírica.

\section{Abstract}

The present article deals with the role that the Galician-Portuguese love-songs attribute to the "eyes" and the "heart", as important factors in the process of falling in love. First of all, we verify the meaning and the presence of motives associated to both terms in those literatures that could have transmitted them to the Iberian Peninsula, and how they relate to similar examples found in the Galician-Portuguese lyric; we then examine three love-songs (Martim Moxa, B 891/ V 475; D. Dinis, B 523/ V 106; João Garcia de Guilhade, $A$ 237), seeking to determine specific uses of those motives in this poetry. 


\section{Anexo}

Cantigas onde co-ocorre o par de termos "olhos"/ "olhus"/ "ollos" e "coraçon"/ "coraçom" (MedDB 2.0.3)

Afonso Lopes de Baião:

Senhor, que grav' oj' a mi é

Afonso Mendes de Besteiros:

Coitado vivo, á mui gran sazon

Airas Nunes:

Oi og' eu ua pastor cantar

Par Deus, coraçon, mal me matades

D. Dinis:

A mha senhor que eu por mal de mi

Non sei como me salv' a mia senhor

Punh'eu, senhor, quanto poss'em quitar

Que prazer avedes, senhor

Senhor fremosa, non poss' eu osmar

(25.114) (NA)

Fernando Esquio:

Senhor, por que tant' afam levey

Fernão Figueira de Lemos:

Ay mia senhor! sempr' eu esto temi

Fernão Garcia Esgaravunha:

Quand'eu mha senhor conhoci

Quen vos foy dizer, mia sennor

Sennor fremosa, conven-mi a rogar

Fernão Gonçalves de Seabra:

Gradesc' a Deus que me vejo morrer

(44.2) (NA)

Fernão Padron:

Nulh' ome non pode saber

Os meus olhos, que mia senhor

Fernão Rodrigues de Calheiros:

Non vus façan creer, senhor

Ora faz a min mia senhor 
Fernão Velho:

Poys Deus non quer que eu ren possa aver

João Garcia de Guilhade:

Esso muy pouco que oj' eu faley

Estes meus olhos nunca perderán

Quexey-m' eu d' estes olhos meus

João Lopes de Ulhoa:

Quand' eu podia mia senhor

João Mendes de Briteiros:

Eya, senhor, aque-vos min aqui!

Tal ventura quis Deus a min, sen[h]or

João Soares Somesso:

Ua donzela quig' eu mui gran ben

João Soares Coelho:

Non me soub' eu dos meus olhos melhor

Nunca coitas de tantas guisas vi

Senhor, por Deus que vus fez parecer

(79.50) (NA)

Martim Moxa:

O gram prazer e gram viç' en cuydar

Martim Peres Alvim:

Senhor fremosa, que de coraçon

Senhor, non poss'eu já per nulha ren

Martim Soares:

Pero que punh' en me guardar

Quando me nenbra de vos, mha senhor

Nuno Eanes Cêrzeo:

Senhor, que coitad' og' eu no mundo vivo

Nuno Fernandes Torneol:

Por Deus, senhor, en gran coita serei

(106.13) (NA)

Osoiro Eanes:

Cuidei eu de meu coraçon

Pai Gomes Charinho:

A mia sennor, que por mal destes meus

Senhor fremosa, tan de coraçon 
Pero Garcia Burgalês:

Mentre non soube por min mia sennor

Pois contra vos non me val, mia sennor

(125.22)

Sennor, queixo me con pesar

(125.35) (NA)

(125.53)

Pero Mendes da Fonseca:

Sazon sey eu que non ousey dizer

Rodrigo Eanes Redondo:

Pois ora faz [Deus] qu(e) eu viver aqui

(141.5) (NA)

Roi Pais de Ribela:

A mha senhor que mui de coraçon

Rui Queimado:

Pois minha senhor me manda

(148.16) (NA)

Vasco Gil:

Punhar quer'ora de fazer

Que partid' eu serei, senhor

Senhor fremosa, pois pesar avedes

(152.8) (NA)

Se vus eu ousasse, sennor

Anônimo:

Pero eu vejo aqui trobadors

(157.39) (NA)

Anônimo:

Pois m’ en tal coita ten Amor (atrib. a João Peres de Aboim)(157.42) (NA) 